\title{
METODE PRAKTIS ESTIMASI MODEL-MODEL PROBABILISTIK PADA ANALISIS FREKUENSI BANJIR UNTUK PRAKTISI PENYELENGGARA INFRASTRUKTUR DI KALIMANTAN SELATAN
}

\author{
Aqli Mursadin ${ }^{1}$, Erika Zeannyta ${ }^{2}$ \\ ${ }^{1}$ Staff Pengajar Program Studi Magister Teknik Sipil Universitas Lambung Mangkurat \\ ${ }^{2}$ Mahasiswa Program Studi Magister Teknik Sipil Universitas Lambung Mangkurat \\ E-mail: a.mursadin@ulm.ac.id/HP.+6285821194410
}

\begin{abstract}
ABSTRAK
Sebuah metode praktis diusulkan untuk keperluan estimasi model-model probabilistik pada analisis frekuensi banjir. Ini merupakan sebuah implementasi tepat guna dari metode estimasi berbasis Lmoments. Model-model yang dimaksud meliputi sejumlah distribusi nilai ektrem, yaitu Gumbel, generalized extreme value, lognormal tiga parameter, Pearson tipe III, log-Pearson tipe III, generalized logistic, dan generalized Pareto. Data untuk keperluan pengujian diambil dari aliran maksimum di dunia nyata. Metode yang diusulkan berupa sebuah prosedur sederhana empat tahap pada aplikasi pengolah spreadsheet. Tidak ada pengodean yang diperlukan. Validasi dilakukan dalam bentuk perbandingan terhadap hasil-hasil menggunakan perangkat lunak komputasi statistik R. Kesederhanaan metode ini bersama dengan kinerja estimasinya yang relatif tinggi berpotensi untuk memungkinkannya diadopsi oleh kalangan praktisi penyelenggara konstruksi, khususnya di Kalimantan Selatan. Rekomendasi untuk pengembangan lanjutan juga diberikan.
\end{abstract}

Kata kunci: analisis frekuensi banjir, estimasi parameter, L-moments

\begin{abstract}
A practical method is proposed for the purpose of estimating probabilistic models in flood frequency analysis. This is an intermediary implementation of estimation based on L-moments. The models include a number of extreme value distributions, namely, Gumbel, generalized extreme value, three-parametric lognormal, Pearson type III, log-Pearson type III, generalized logistic, and generalized Pareto. Test data are obtained as real-world maximum flows. The proposed method is a four-step procedure run on a spreadsheet processing application. No coding is required. Validation is carried out in the form of comparison against results obtained using statistical software $R$. The simplicity of the method along with its relatively high estimation performance can potentially make it considered for adoption by practitioners in the construction industry, especially in South Kalimantan. Recommendations for future work are also given.
\end{abstract}

Keywords: flood frequency analysis, L-moments, parameter estimation 


\section{PENDAHULUAN}

Analisis nilai ekstrem dari data hidrologis memainkan peranan penting untuk menyediakan informasi dalam perencanaan infrastruktur (Kottegoda \& Rosso, 1997:465). Salah satu pendekatan untuk memahami perilaku yang demikian adalah analisis frekuensi banjir (flood frequency analysis) yang berdasarkan pada distribusi nilai ekstrem dari debit-debit aliran yang berkaitan (Roy \& De, 2015).

Metode-metode praktis pada perencanaan yang berdasarkan pada analisis yang demikian cukup umum dikuasai oleh pihak-pihak yang berkepentingan seperti praktisi penyelenggara infrastruktur, khususnya di Kalimantan Selatan. Walaupun demikian, model-model probabilistik yang digunakan biasanya tersedia dengan pilihan jenis yang terbatas (seperti Pearson Tipe III dan lognormal), sementara itu, beberapa publikasi terakhir di bidang ini telah mengeksplorasi keberhasilan beberapa model nilai ekstrem lainnya (Shabri, dkk., 2011; Bilková, 2012; Bilková, 2014, Khan, dkk., 2017).

Selanjutnya, metode estimasi yang selama ini umum digunakan adalah metode momen yang cukup praktis tetapi cenderung mengabaikan kehadiran outliers sehingga kurang mampu mengakomodasi nilai-nilai ekstrem di ujung-ujung urutan data. Metode lain yang juga umum digunakan adalah metode maximum likelihood yang sangat baik untuk data berukuran besar tetapi memerlukan komputasi yang intensif.

Sebuah metode lain yang belum cukup dikenal tetapi mulai menarik banyak minat di kalangan akademisi adalah metode estimasi L-moment (Hosking, 1990; Hosking \& Wallis, 1997; Shabri \& Ariff, 2010; Hassan, dkk., 2019). Metode ini memertimbangkan pembobotan probabilitas sehingga sangat sesuai untuk nilai-nilai ekstrem. Komputasi yang intensif dapat menjadi penghalang untuk adopsi metode ini di kalangan praktisi. Walaupun demikian, dengan perkembangan teknologi perangkat lunak populer seperti saat ini, implementasi metode ini berpotensi diterapkan menggunakan pengolah spreadsheet tanpa memerlukan pengodean (coding) sedikitpun.

Artikel ini membahas implementasi metode estimasi L-moment di atas pada sebuah aplikasi pengolah spreadsheet. Implementasi ini bertujuan untuk menjadikan metode estimasi L-moment ini tersedia sebagai sebuah metode praktis. Selanjutnya, kesederhanaan di dalam pengoperasian dan kemungkinan untuk kostumisasi diakomodasi di dalam implementasi ini.

\section{METODE}

Implementasi dari metode L-moment menjadi sebuah metode praktis berbasis pengolah spreadsheet ini dilaksanakan dalam langkah-langkah berikut:

1. Melakukan tinjauan literatur mengenai analisis frekuensi banjir dan estimasi model-model probabilistik yang berkaitan. Model-model probabilistik yang digunakan adalah distribusidistribusi Gumbel (EV1), generalized extreme value (GEV), distribusi lognormal 3 parameter (LN3), Pearson tipe III (P3), log-Pearson tipe 3 (LP3), generalized logistic (GLO), dan generalized Pareto (GPA).

2. Menyusun prosedur sederhana dari implementasi metode yang bersangkutan menggunakan perangkat lunak Microsoft Excel 2013.

3. Mengumpulkan data untuk pengujian implementasi. 
4. Menganalisis hasil implementasi dan melakukan validasi menggunakan perangkat lunak $\mathrm{R}$ versi 4.0.3 (R Core Team, 2020).

5. Membuat kesimpulan.

Perangkat lunak utama yang digunakan untuk keperluan ini adalah Microsoft Excel 2013 sebagai pengolah spreadsheet. Untuk keperluan validasi digunakan perangkat lunak $\mathrm{R}$ versi 4.0.3 (https://www.R-project.org/).

Data pengujian implementasi adalah data aliran maksimum tahunan Sungai Torne di Swedia pada stasiun nomor 16722 mulai tahun 1911 sampai 2020 (https://vattenwebb.smhi.se/station/). Ini adalah data harian sehingga data maksimum tahunan yang dimaksud masih perlu diekstrak lebih lanjut.

\section{HASIL DAN PEMBAHASAN}

\section{Implementasi}

Hasil implementasi metode ini adalah berupa sebuah prosedur empat tahap sebagai berikut:

1. Pemasukan data aliran maksimum. Gambar 1 mengilustrasikan tahap dan sheet Microsoft Excel yang berhubungan.

2. Proses fitting, yaitu penentuan nilai-nilai estimate dari parameter-parameter model. Gambar 2 mengilustrasikan tahap dan sheet Microsoft Excel yang berhubungan.

3. Pengujian tingkat kesesuaian antara model dan data (goodness of fit test). Gambar 3 mengilustrasikan tahap dan sheet Microsoft Excel yang berhubungan.

4. Pemilihan model terbaik dan penetapan kuantil rencana berdasarkan periode pengulangan. Gambar 4 mengilustrasikan tahap dan sheet Microsoft Excel yang berhubungan.

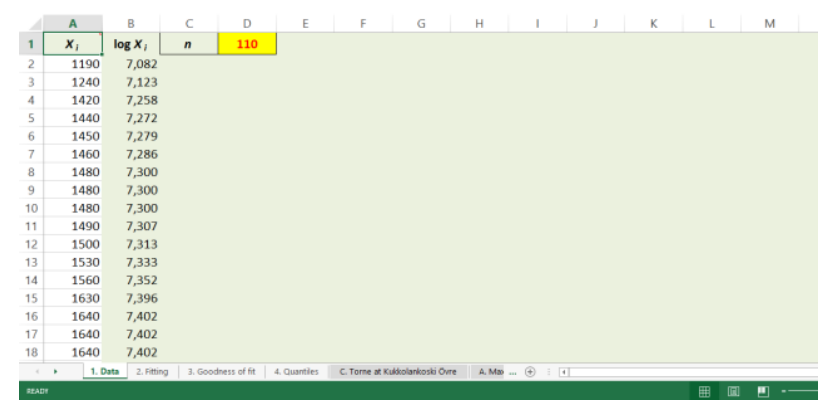

Gambar 1 Tahap pemasukan data

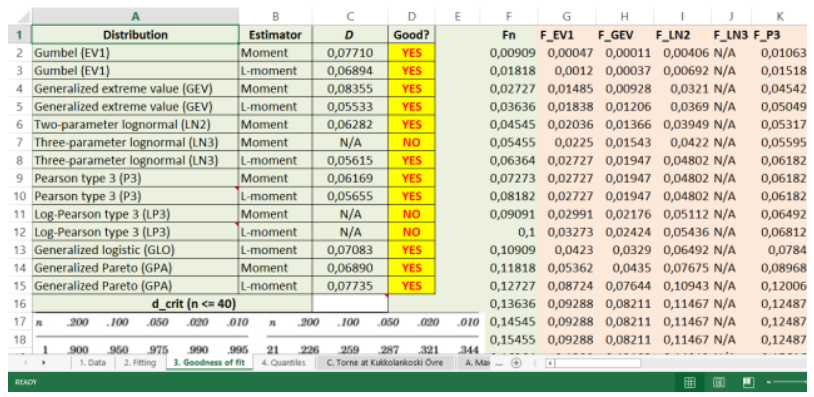

Gambar 3 Tahap pengujian kesesuaian

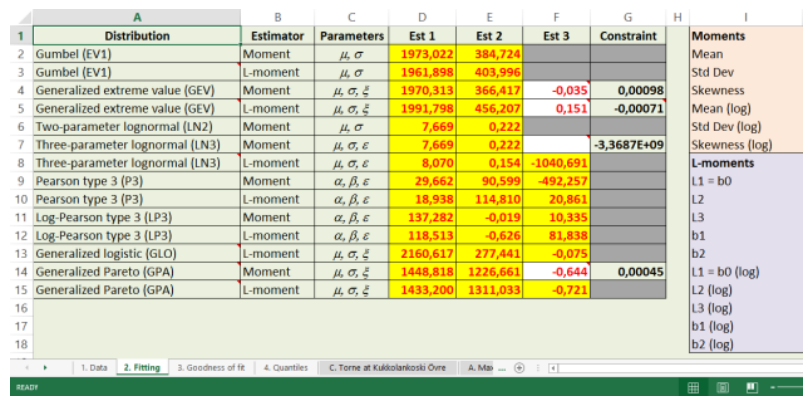

Gambar 2 Tahap fitting

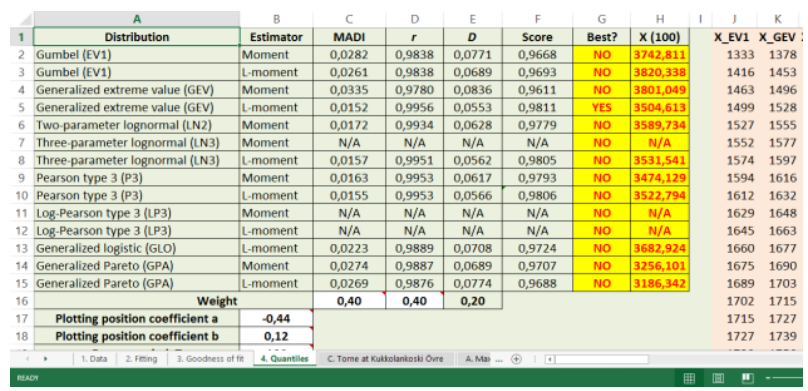

Gambar 4 Tahap pemilihan model dan penentuan kuantil 
Pengguna dapat langsung memasukkan data aliran maksimum pada sheet yang pertama, kemudian mengurutkan titik-titik data yang bersangkutan dari nilai terkecil ke nilai terbesar. Ukuran maksimum dari data yang dapat dimasukkan adalah 1000 titik data.

Pada tahap fitting, pengguna sudah dapat melihat model mana yang sesuai atau yang dapat diestimasi untuk data yang dimaksud. Untuk data yang berbeda, beberapa model tertentu mungkin tidak dapat diestimasi. Untuk beberapa model tertentu, berlaku sebuah persamaan kendala (constraint) yang nilainya mendekati nol dan harus diselesaikan untuk parameter ketiga dari model yang bersangkutan. Ini akan merupakan interaksi paling rumit di antara pengguna dan aplikasi, di mana pengguna akan mencari solusi tersebut menggunakan fasilitas Goal seek dari Microsoft Excel.

Hasil pengujian pada tahap berikutnya menunjukkan model-model mana yang kesesuaiannya memadai (good fit) terhadap data. Metode pengujian yang digunakan adalah pengujian Kolmogorov-Smirnov.

Tahap terakhir adalah tahap pemilihan model dan penentuan kuantil rencana. Pemilihan model didasarkan pada kombinasi antara nilai statistik uji Kolmogorov-Smirnov, akurasi berdasarkan mean absolute deviation index (Jain \& Singh, 1986), dan nilai koefisien korelasi Pearson di antara data dan prediksi yang dihasilkan model. Kuantil yang dihasilkan dari model terpilih dengan sendirinya menjadi kuantil rencana yang direkomendasikan.

Dengan data uji yang digunakan, semua model yang dipertimbangkan dapat diestimasi. Hasil estimasi dari parameter-parameter model yang bersangkutan diperlihatkan pada Tabel 1.

Tabel 1 Hasil estimasi menggunakan data uji

\begin{tabular}{|l|r|r|r|}
\hline \multirow{2}{*}{\multicolumn{1}{c|}{ Distribusi }} & \multicolumn{3}{c|}{ Estimate } \\
\cline { 2 - 4 } & Parameter 1 & \multicolumn{1}{c|}{ Parameter 2 } & Parameter 3 \\
\hline Gumbel (EV1) & 1961,898 & 403,996 & - \\
\hline Generalized extreme value (GEV) & 1991,798 & 456,207 & 0,151 \\
\hline Three-parameter lognormal (LN3) & 8,070 & 0,154 & $-1040,691$ \\
\hline Pearson type III (P3) & 18,938 & 114,810 & 20,861 \\
\hline Log-Pearson type III (LP3) & 118,513 & $-0,626$ & 81,838 \\
\hline Generalized logistic (GLO) & 2160,617 & 277,441 & $-0,075$ \\
\hline Generalized Pareto (GPA) & 1433,200 & 1311,033 & $-0,721$ \\
\hline
\end{tabular}

Walaupun demikian, ini belum merupakan jaminan bahwa model-model tersebut layak digunakan. Hasil pengujian Kolmogorov-Smirnov untuk data yang bersangkutan menunjukkan bahwa satu model, yaitu log-Pearson tipe III, tidak memiliki kesesuaian yang memadai terhadap data (lihat Tabel 2). Ukuran yang digunakan adalah nilai $D$. Jika nilai ini lebih kecil daripada 0,130 , maka model yang bersangkutan dikatakan sesuai. Sebaliknya, jika selain itu, maka model yang bersangkutan dikatakan tidak sesuai.

Pada tahap terakhir, dilakukan pemilihan berdasarkan akurasi model. Ukuran untuk ini adalah rata-rata berbobot (skor) di antara akurasi berdasarkan mean absolute deviation index (MADI), nilai koefisien korelasi Pearson $(r)$, dan nilai $D$. Untuk kasus ini, bobot-bobot yang dipilih masing-masing adalah 0,4 untuk $1-M A D I, 0,4$ untuk $r$, dan 0,2 untuk $1-D$. Pengguna dapat 
memilih nilai-nilai yang lain selama jumlah total dari nilai-nilai tersebut sama dengan satu. Tabel 3 memberikan hasil pemilihan yang dimaksud berdasarkan data uji. Dalam hal ini, periode pengulangan yang digunakan adalah 100 tahun. Kuantil rencana yang terpilih adalah 3504,613 $\mathrm{m}^{3} / \mathrm{s}$ yang diberikan oleh model terbaik (GEV).

Tabel 2 Hasil pengujian Kolmogorov-Smirnov

\begin{tabular}{|l|c|c|}
\hline \multicolumn{1}{|c|}{ Distribusi } & $\boldsymbol{D}$ & Sesuai \\
\hline Gumbel (EV1) & 0,06894 & Ya \\
\hline Generalized extreme value (GEV) & 0,05533 & Ya \\
\hline Three-parameter lognormal (LN3) & 0,05615 & Ya \\
\hline Pearson type III (P3) & 0,05655 & Ya \\
\hline Log-Pearson type III (LP3) & N/A & Tidak \\
\hline Generalized logistic (GLO) & 0,07083 & Ya \\
\hline Generalized Pareto (GPA) & 0,07735 & Ya \\
\hline
\end{tabular}

Tabel 3 Hasil pemilihan model berdasarkan data uji dan kuantil $\left(\mathrm{m}^{3} / \mathrm{s}\right)$ yang bersangkutan

\begin{tabular}{|l|c|c|c|c|c|c|}
\hline \multicolumn{1}{|c|}{ Distribusi } & MADI & $\boldsymbol{r}$ & $\boldsymbol{D}$ & Skor & Pilih & Kuantil \\
\hline Gumbel (EV1) & 0,0261 & 0,9838 & 0,0689 & 0,9693 & Tidak & 3820,338 \\
\hline Generalized extreme value (GEV) & 0,0152 & 0,9956 & 0,0553 & 0,9811 & Ya & 3504,613 \\
\hline Three-parameter lognormal (LN3) & 0,0157 & 0,9951 & 0,0562 & 0,9805 & Tidak & 3531,541 \\
\hline Pearson type III (P3) & 0,0155 & 0,9953 & 0,0566 & 0,9806 & Tidak & 3522,794 \\
\hline Log-Pearson type III (LP3) & N/A & N/A & N/A & N/A & Tidak & N/A \\
\hline Generalized logistic (GLO) & 0,0223 & 0,9889 & 0,0708 & 0,9724 & Tidak & 3682,924 \\
\hline Generalized Pareto (GPA) & 0,0269 & 0,9876 & 0,0774 & 0,9688 & Tidak & 3186,342 \\
\hline
\end{tabular}

Secara keseluruhan, metode ini dapat dijalankan dalam waktu 3 menit pada sebuah note book sederhana dengan prosesor Intel® Core i3. Tidak ada alat bantu komputasi lain atau tabel-tabel yang diperlukan untuk estimasi semua model ini.

\section{Validasi}

Validasi dari model ini dilakukan dengan melihat kesesuaian hasil estimasinya terhadap hasil estimasi dengan metode L-moment menggunakan aplikasi khusus untuk komputasi statistik, yaitu R dengan paket "lmom" (Hosking, 2019). Komputasi kesalahan baku dan interval keyakinan diberikan melalui teknik bootstrapping menggunakan paket "boot" (Canty \& Ripley, 2020) dari R. Komputasi ini cukup kompleks karena memerlukan pengodean (coding) sehingga tidak direkomendasikan untuk penggunaan praktis.

Tabel 4 memberikan hasil estimasi yang dimaksud beserta kesalahan baku dan interval keyakinan 95 persen (di antara batas bawah dan batas atas) untuk setiap nilai parameter yang bersangkutan. Secara keseluruhan dapat terlihat adanya konsistensi dan kedekatan numerik yang tinggi di antara hasil-hasil dari metode praktis yang dikembangkan menggunakan aplikasi spreadsheet (Tabel 1) dan yang diperoleh menggunakan aplikasi spesifik seperti R.

Setiap interval yang dimaksud memiliki tingkat keyakinan 95 persen. Sebagai contoh, parameter ke-1 dari GEV yang diestimasi sebesar 1992 memiliki nilai sebenarnya yang dapat diyakini berada di antara 1902 dan 2101 dengan tingkat keyakinan 95 persen. Semakin sempit interval 
ini, semakin akurat hasil estimasi yang diberikan. Beberapa kesalahan baku dan interval keyakinan gagal ditemukan untuk tiga model, yaitu lognormal tiga parameter, Pearson tipe III, dan log-Pearson tipe III. Ini berarti bahwa ketiga model tersebut sebaiknya tidak dipertimbangkan lebih lanjut karena validitas hasil estimasi yang bersangkutan tidak tercapai.

Tabel 4 Hasil validasi

\begin{tabular}{|c|c|c|c|c|c|}
\hline Distribusi & Parameter & Estimate & $\begin{array}{c}\text { Kesalahan } \\
\text { baku }\end{array}$ & $\begin{array}{r}\text { Batas } \\
\text { bawah }\end{array}$ & $\begin{array}{c}\text { Batas } \\
\text { atas }\end{array}$ \\
\hline \multirow[t]{2}{*}{ Gumbel (EV1) } & 1 & 1962 & 3,46 & 1879 & 2059 \\
\hline & 2 & 404 & 26,6 & 348 & 452 \\
\hline \multirow{3}{*}{$\begin{array}{l}\text { Generalized extreme } \\
\text { value (GEV) }\end{array}$} & 1 & 1992 & 50,6 & 1902 & 2101 \\
\hline & 2 & 457 & 35,4 & 385 & 524 \\
\hline & 3 & 0,153 & 0,0577 & 0,043 & 0,280 \\
\hline \multirow{3}{*}{$\begin{array}{l}\text { Three-parameter } \\
\text { lognormal (LN3) }\end{array}$} & 1 & 8,07 & 0,618 & 7,39 & 9,72 \\
\hline & 2 & 0,154 & 0,0702 & 0,00430 & 0,293 \\
\hline & 3 & -1041 & - & - & - \\
\hline \multirow[t]{3}{*}{ Pearson type III (P3) } & 1 & 18,9 & - & - & - \\
\hline & 2 & 115 & - & - & - \\
\hline & 3 & 20,9 & - & - & - \\
\hline \multirow[t]{3}{*}{ Log-Pearson type III (LP3) } & 1 & 119 & - & - & - \\
\hline & 2 & $-0,626$ & - & - & - \\
\hline & 3 & 81,8 & - & - & - \\
\hline \multirow[t]{3}{*}{ Generalized logistic (GLO) } & 1 & 2161 & 53,2 & 2065 & 2272 \\
\hline & 2 & 277 & 18,5 & 238 & 310 \\
\hline & 3 & $-0,0750$ & 0,0342 & $-0,142$ & $-0,00210$ \\
\hline \multirow[t]{3}{*}{ Generalized Pareto (GPA) } & 1 & 1433 & 63,1 & 1318 & 1573 \\
\hline & 2 & 1311 & 175 & 1025 & 1712 \\
\hline & 3 & $-0,721$ & 0,120 & $-0,992$ & $-0,502$ \\
\hline
\end{tabular}

\section{PENUTUP}

\section{Kesimpulan}

Beberapa hal penting yang dapat disimpulkan adalah sebagai berikut:

1. Metode L-moment dapat diimplementasikan menjadi sebuah metode yang praktis pada perangkat komputasi sederhana. Ini berpotensi untuk memungkinkan adopsi dari metode yang akurat ini oleh kalangan praktisi penyelenggara konstruksi, khususnya di Kalimantan Selatan.

2. Implementasi ini memberikan hasil yang konsisten secara numerik terhadap hasil-hasil yang diperoleh menggunakan perangkat lunak komputasi yang memang didedikasikan untuk keperluan estimasi.

\section{Rekomendasi}

Untuk pengembangan lebih lanjut, dapat direkomendasikan

1. Perluasan menggunakan model-model nilai ekstrem yang lain seperti Weibull tiga parameter, Fréchet tiga parameter, kappa empat parameter, dan Wakeby lima parameter. 
2. Implementasi praktis untuk persoalan-persoalan nilai ekstrem selain persoalan aliran maksimum, seperti persoalan-persoalan nilai minimum untuk kekeringan, tinggi ekstrem gelombang, kekuatan gempa, dan lain-lain.

\section{Ucapan Terima Kasih}

Penulis menyampaikan terima kasih kepada Program Studi Magister Teknik Sipil Universitas Lambung Mangkurat yang telah mendanai kegiatan pengabdian kepada masyarakat ini.

\section{DAFTAR PUSTAKA}

1. Bikova, D. 2012. Lognormal Distribution and Using L-moment Method for Estimating Its Parameters. Int. J. Mathematical Models and Methods in Applied Sciences, 6 (1), 30-44.

2. Bilkova, D. 2014. Alternative Means of StatData An.: L-Moments and TL-Moments of Prob Distibutions. Statistika, 94 (2), 77-94.

3. Canty, A. and B. Ripley. 2020. boot: Bootstrap R (S-Plus) Functions. R package version 1.325.

4. Hassan, M. U., O. Hayat, and Z. Noreen. 2019. Selecting the best probability distribution for at-site food frequency analysis; a study of Torne River. SN Applied Sciences. URL: https://link.springer.com/article/10.1007/s42452-019-1584-z (last accessed 10 May 2021).

5. Hosking, J. R. M. 1990. L-moments: Analysis and estimation of distributions using linear combinations of order statistics. J. Royal Statistical Society B, 52, 105-24.

6. Hosking, J. R. M. 2019. L-Moments. R package, version 2.8. URL: https://CRAN.Rproject.org/package $=$ lmom.

7. Hosking, J. R. M. and J. R. Wallis. 1997. Regional Frequency Analysis - An Approach Based on L-Moments. Cambridge, UK: Cambridge Univ. Press.

8. Hosking, J. R. M., J. R. Wallis, and E. F. Wood. 1985. Estimation of the GEV Distribution by the Method of PWMs. Technometrics, 27 (3), 251-61.

9. Jain, D. and V. A. Singh. 1986. Comparison of transformation methods for flood frequency analysis, Water Resources Bulletin, 22 (6), 903-12.

10. Khan, S. A., I. Hussain, T. Hussain, M. Faisal, Y. S. Muhammad, and A. M. Shoukry. 2017. Regional Frequency Analysis of Extremes Precipitation Using L-Moments and Partial LMoments, India. Advances in Meteorology. URL: https://doi.org/10.1155/2017/6954902 (last accessed 10 May 2021).

11. Kottegoda, N. T. dan R. Rosso. 1997. Statistics, Probability, and Reliability for Civil and Environmental Engineers. Singapore: McGraw-Hill Co.,Inc.

12. R Core Team. 2020. R: A language and environment for statistical computing. R Foundation for Statistical Computing, Vienna, Austria. URL https://www.R-project.org/.

13. Roy, P. and S. K. De. 2015. A Comparative Approach to Flood Frequency Analysis of the Puthimari River in Assam, India. Asian J. Spatial Sc., 3, 90-9.

14. Shabri, A. and N. M. Ariff. 2010. On Selection of Probability Distributions of Annual Maximum Daily Rainfalls Using TL-Moments. Matematika, 26 (2), 137-51.

15. Shabri, A., U. N. Ahmad, and Z. A. Zakaria. 2011. TL-moments and L-moments Estimation of the Generalized Logistic Distribution. J. Mathematics Research, 3 (1), 97-106. 